\title{
Arquitectura religiosa afroamericana: una producción híbrida en la búsqueda de la identidad. La capilla de San Miguel en Paraná, Argentina
}

\author{
Afro-American religious architecture: a hybrid production in the search \\ for identity. The Chapel of San Miguel in Paraná, Argentina
}

\author{
Daniel Schávelzon ${ }^{1}$ \\ Centro de Arqueología Urbana, Universidad de Buenos Aires
}

\begin{abstract}
RESUMEN
Migrantes afros de la ciudad de Santa Fe se instalaron en un lugar cercano pero protegido, en los inicios del siglo XVIII, donde hoy está la ciudad de Paraná. Allí construyeron ranchos y una capilla, mientras que lentamente creció un asentamiento blanco/criollo en sus cercanías. Después de la Independencia y aprovechando los gobiernos liberales de la década de 1820, se construyó una gran estructura religiosa siguiendo el modelo colonial de las capillas abiertas de indios. Como rechazo a su existencia y significado, y como una manera de cambiarle su función, a partir de 1833 los gobiernos conservadores construyeron en su frente una iglesia católica comenzando lo que sería su ocultamiento. La zona quedó lentamente incluida en la nueva ciudad, urbanizada, y la población migró. Pese a eso, la capilla siguió viva porque la comunidad le fue haciendo adaptaciones, cambios de forma y funcionamiento, adaptándola a la ritualidad católica, para sobrevivir hasta finales del siglo XIX. Los estudios han permitido entender esta construcción que en su estado actual es solo una iglesia más, sin las particularidades que tuvo en su historia.
\end{abstract}

Palabras clave: arquitectura religiosa; población afroargentina; hibridación; arqueología de la arquitectura.

\begin{abstract}
Afro migrants from the city of Santa Fe settled down in a close but protected place, at the beginning of the 18th century. This is today the city of Paraná. They built there several houses and a chapel, while a White/ Creole settlement was slowly growing in the nearby. After Independence, with the liberal governments of the 1820 's, a great structure was made following the colonial model of the Open Chapels of Indians. From 1833 onwards, conservative governments built a Catholic church at the front of the former chapel, beginning thus its concealment. The area was slowly included in the new urbanized city, and the population moved to other areas. Despite these circumstances, the chapel survived until the end of the 19th century thanks to the formal and functional modifications carried out by the community. Interdisciplinary studies have made it possible to understand this construction, currently another Catholic church, which has lost its historical singularities.
\end{abstract}

Key words: religious architecture; Afro-Argentine population; hybridization; Archaeology of Architecture.

Recibido: 27-09-2019. Aceptado: 09-03-2020.

Cómo citar este artículo / Citation

Schávelzon, D. 2020: "Arquitectura religiosa afroamericana: una producción híbrida en la búsqueda de la identidad. La capilla de San Miguel en Paraná, Argentina", Arqueología de la Arquitectura, 17: e106. https://doi.org/10.3989/arq.arqt.2020.014

Copyright: (C) CSIC, 2020. (c) UPV/EHU Press, 2020. Este es un artículo de acceso abierto distribuido bajo los términos de la licencia de uso y distribución Creative Commons Reconocimiento 4.0 Internacional (CC BY 4.0). 
En la ciudad de Paraná, Argentina, existen dos iglesias una al lado de la otra, con igual nombre: "San Miguel Arcángel”; eso llama la atención. Una es habitualmente llamada "la capilla" y está fuera de uso (Figs. 1 y 2), la otra es "la iglesia" por ser mucho más grande y estar abierta. Ésta da su frente a una gran plaza, la otra quedó invisible a sus espaldas, estando clausurada por un siglo y con el acceso a través de un angosto pasillo entre muros. La iglesia mayor ha sido considerada desde su construcción (inaugurada en 1873) como el segundo mayor monumento de la ciudad después de la catedral, la capilla ha sido recordada solo por los recientes historiadores de la arquitectura pero por su unicidad estética para la década de 1820 , fecha que se atribuye para su construcción. Fue declarada Monumento Nacional por la presión de la comunidad afro por sus derechos y no por su significación en la ciudad. La historia local ha denominado a esa capilla como "la capilla de los negros" (Cerutti 2007) ya que esa zona fue el Barrio del Tambor o zona del primer poblamiento afro.

En el año 2017 se inició la restauración de la capilla como parte de la recuperación de los derechos de los grupos afro-paranaenses, pero el proyecto llevó a que, si bien se la destacara y se le diera una vista digna desde la calle, se consolidara su imagen como un edificio religioso católico más, incluso desde el exterior tomó forma basilical, lo que nunca tuvo (Schávelzon y Martínez 2017). $\mathrm{Su}$ recuperación, a la vez que permitió estudios que contradecían esa imagen final, fue el cierre de un proceso de dos siglos que partió de un rancho simple y modesto de la población afro, una historia olvidada y por cierto desconocida porque fue hecha invisible, olvidada, desdibujada.

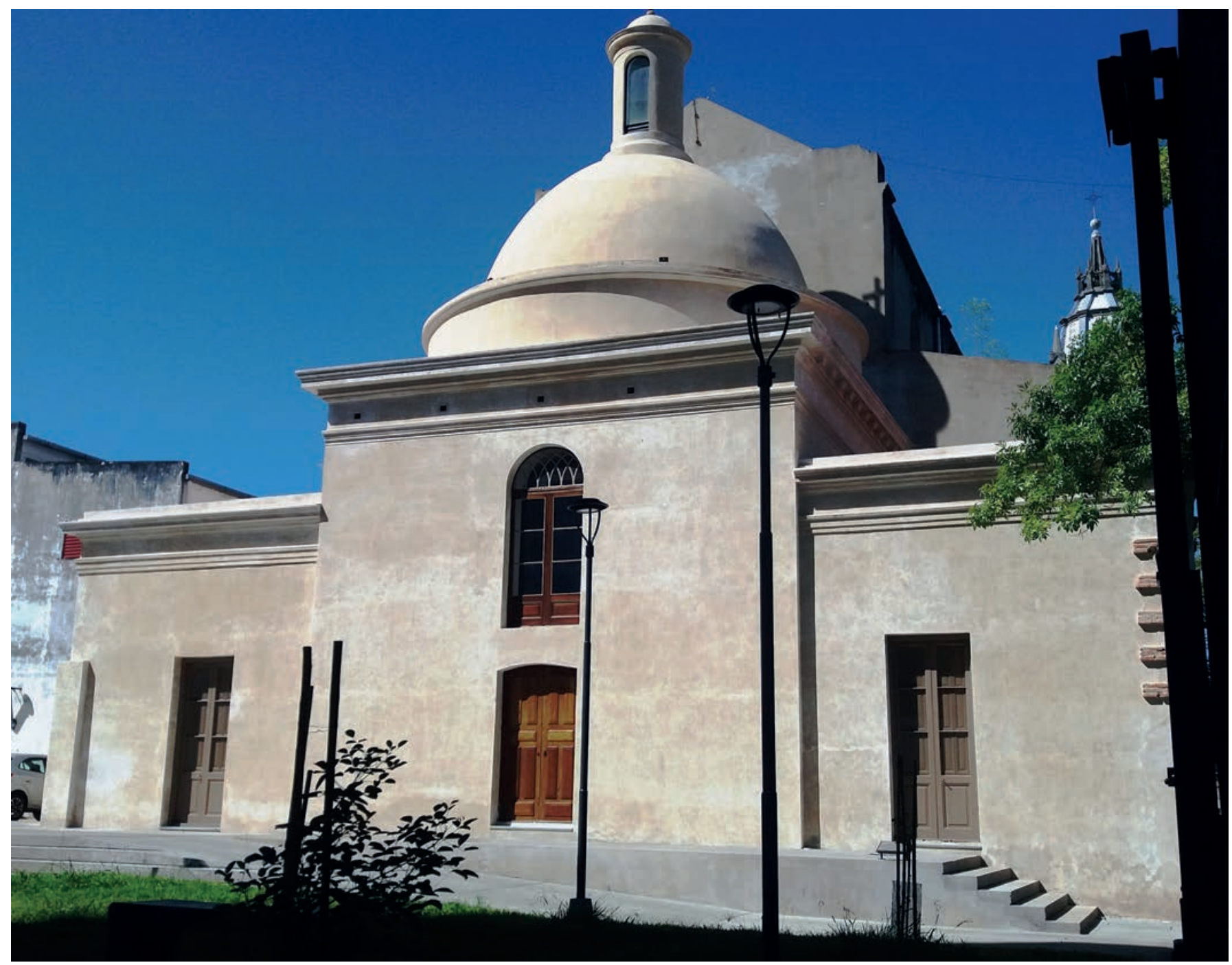

Figura 1. La capilla de San Miguel Arcángel al terminar los trabajos de restauración en 2019; se ve a su espalda la parte posterior de la iglesia de igual nombre. Fotografía: A. Richard. 


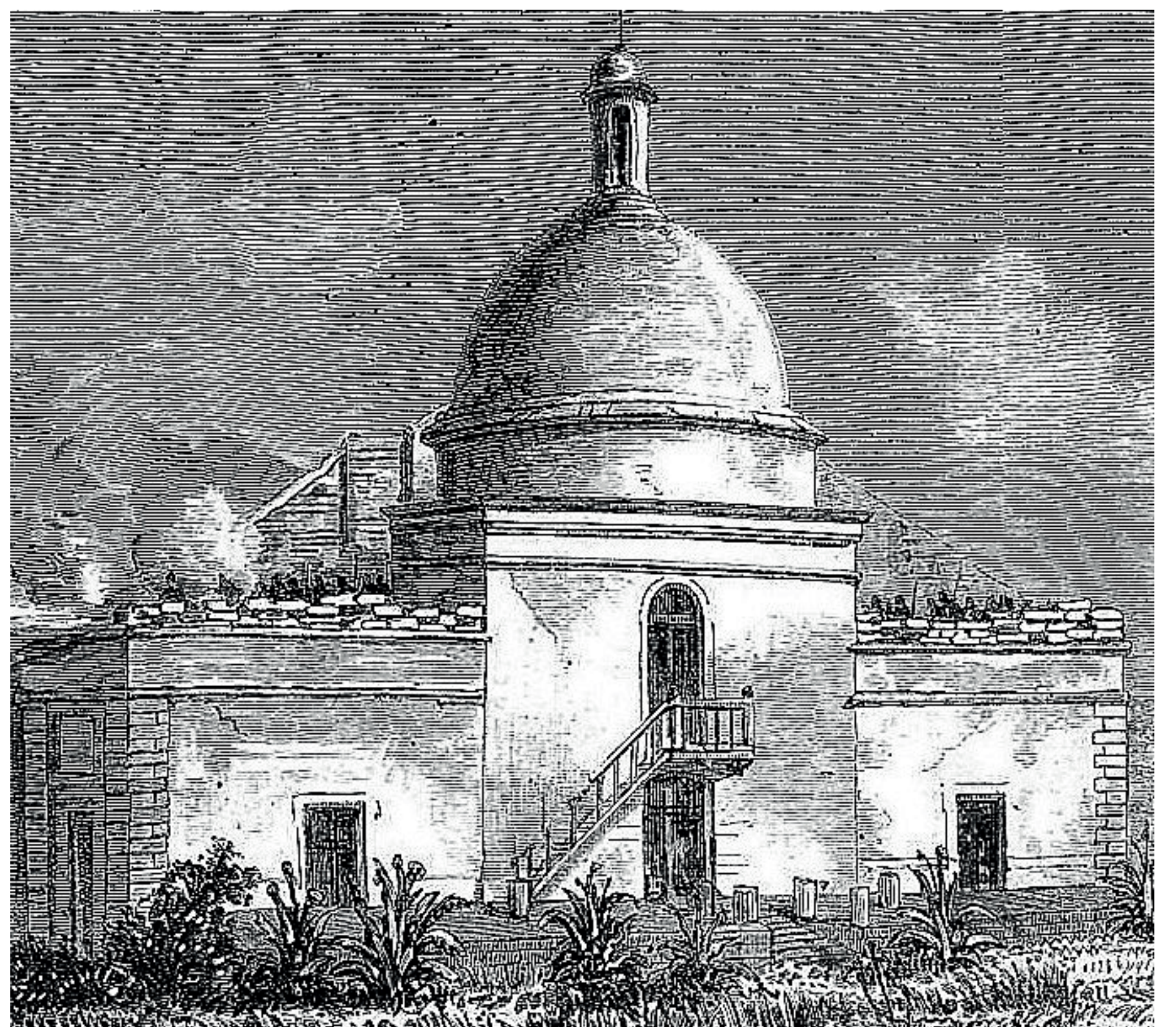

Figura 2. Fachada de la capilla de San Miguel en 1871 con un balcón-capilla, la escalera de acceso externa y el atrio abierto hacia el sur; detrás la iglesia en construcción está desdibujada. Litografía de H. Meyer publicada en El Americano 46: 145, París, febrero 1874.

La gran iglesia que se construyó a su lado después de un siglo, terminó triunfando no solo por sus dimensiones, no por tapar a la otra, sino -físicamente hablando- gracias a una restauración que en lugar de regresarla a su forma original cerró para el futuro la imagen de sus formas originales pasando a ser otra iglesia más.

\section{LA CIUDAD DE PARANÁ}

La ciudad de Paraná es, en la historia argentina, un asentamiento del siglo XVIII sin fecha precisa de fundación
(Fig. 3). Se adoptó para cuestiones simbólicas la fecha del inicio de la construcción de la catedral, lo que de por sí es significativo. La realidad documental es que allí se fueron asentando pobladores afros en un lugar que está separado por el gran río Paraná de la gran ciudad de Santa Fe o su cercana Coronda, y protegida por altas barrancas y en donde los originarios pueblos indígenas ya habían sido combatidos y expulsados para usar la tierra para el ganado (Guillot 1961; Saguier 1995; Cerutti 2010). Los primeros afros pudieron o no ser cimarrones, pero la descripción más antigua del lugar decía que: 


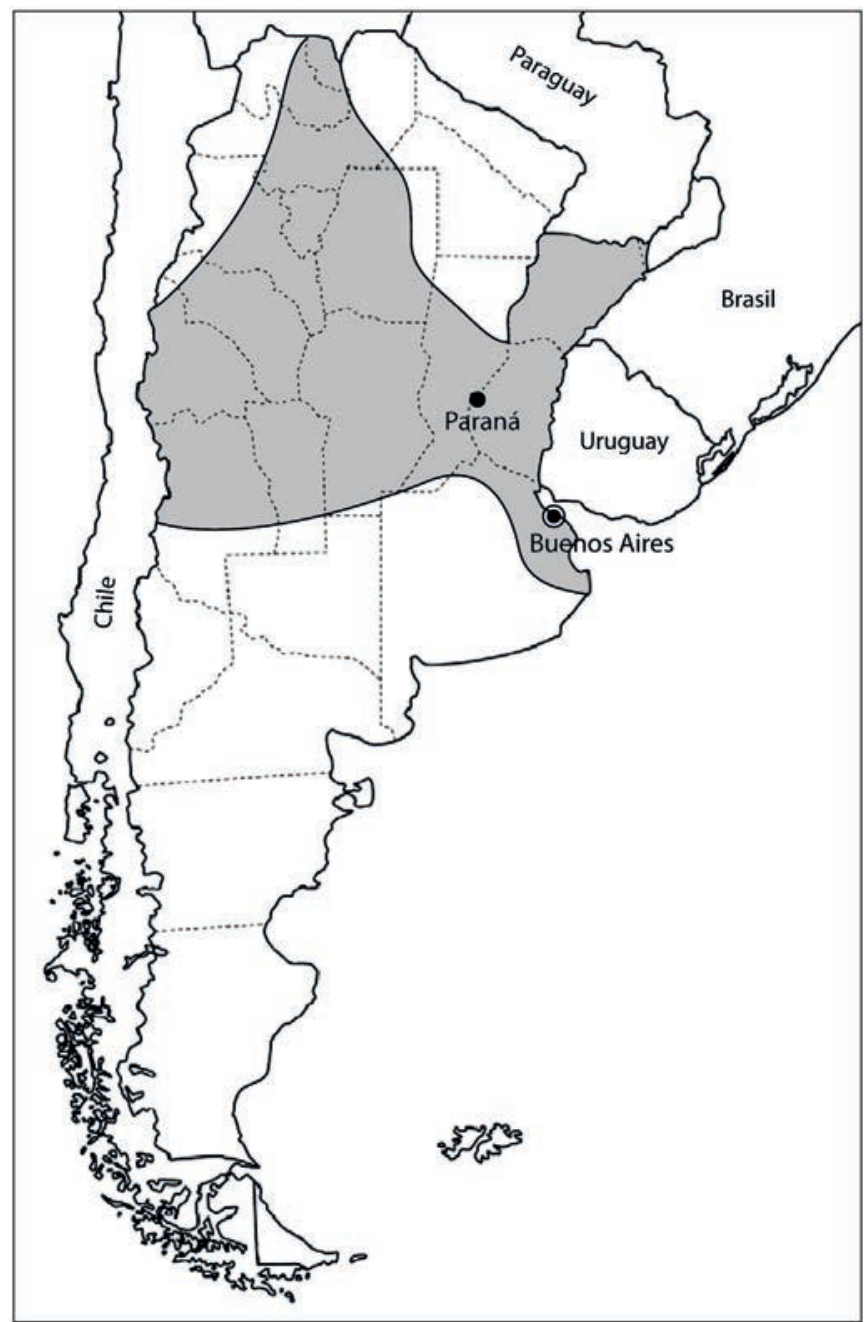

Figura 3. Territorio que conformaba la Argentina de mitad del siglo XIX y la ubicación de la ciudad de Paraná. Dibujo: F. Girelli.

A principios de este siglo pasaron los tres primeros vecinos de Coronda afligidos de la persecución de los (indios) Abipones, a poco pasaron sus ganaditos y uno después de otro se situaron donde les pareció mejor. Por el año 1740 ya tenían capilla, cuyos primeros ranchos alrededor fueron de unos pardos (Aguirre 1951: 17).

Es posible que se estuviera hablando de una primera y muy modesta capilla ubicada en donde aún está la de San Miguel, lugar estratégico desde la lógica topográfica en el punto más alto de la subida desde el puerto al poblado.

Con los años se hizo un lugar de población mixta compuesta por criollos, afros, españoles e indígenas, de gran heterogeneidad, caracterizando el lugar como un territorio de frontera. En la zona los jesuitas desde temprano explotaban la cal y tenían ganados. Fue lógico que en el siglo XX la historia tradicional se escribiera destacando los inicios de la ciudad como de lucha contra el indio enemigo para exaltar la epopeya blanca que llegó a establecer un gobierno colonial-eclesiástico en el mismo lugar (Pérez Colman 1930, 1937, 46; Sors 1981). Las tierras pasaron a tener valor y los derechos a la propiedad comenzaron a escriturarse en 1778 (Pérez Colman 1930, 1946; Reula 1963; Sors 1981).

El asentamiento se inició con un sitio en que se amarraban los botes sobre la orilla de un brazo del río, lugar aún llamado Puerto Viejo, y con un conjunto de ranchos en la parte alta de la barranca, unidos por un camino empinado de subida, creando así el primer núcleo de ocupación. No resulta casual que ese camino unía directo el puerto con la capilla y aún lo sigue haciendo. Poco más tarde comenzaron a pasar a esas tierras pobladores criollos y blancos para la explotación de la creciente ganadería y las caleras, usando el puerto y el camino e instalándose a poca distancia del sitio originario, a un kilómetro escaso. Los jesuitas explotaban allí canteras de cal desde hacía tiempo pero no hay datos de la relación entre estos y la población afro ya instalada. Pero al parecer la ocupación del terreno fue desde el inicio un mundo escindido. Y por diversas razones el crecimiento de ambas zonas fue diferente: la población criolla aumentaba a ritmo acelerado y la afro se reducía desde que dejaron de entrar esclavizados al país y por el modelo de construcción de una nación que tendía al blanqueamiento y la invisibilización de lo afro.

Paraná a mitad del siglo XIX y aunque por pocos años sería la capital de la Argentina, mostrando un ritmo muy alto de crecimiento. En 1824 contaba con 3654 habitantes empadronados de los que menos de la mitad eran nacidos allí. Al 11.5 \% se le adjudicó la categoría "indio", mientras que se clasificó a un $17.2 \%$ como "pardos", al $4.9 \%$ como "negra" y al restante $66.4 \%$ como "blanca" (Richard 2019). En un censo de 1844 solo había 29 esclavos lo que representa el $0.6 \%$ de los habitantes. Pero las cifras no hacen referencia a la población no censada que debió ser en su mayoría negra y marginal (Ceruti 2007). Es un buen ejemplo de lo que pasaba en todo el país en esos años posteriores a la Independencia ¿Nos permite esto aplicar las estadísticas de otros sitios de la región? Una generación antes, en Buenos Aires la población afro era de un $30 \%$ o más. Por lo que, pese a que hay pocos datos, estos nos permiten comprender que era un grupo minoritario pero no menor, que tenían un poder de negociación, y que fue lo bastante como para lograr mantener y hasta ampliar una capilla en un sitio importante, y llevar más tarde al gobierno a hacer obras para ocultarlos pero 
sin alterar totalmente lo existente. Se los podía desconocer pero no demoler la capilla.

Ambos asentamientos tuvieron historias similares como fue la transformación acelerada de su sitios de culto (la catedral y la capilla): ambas crecerían, tendrían cambios significativos -las dos dieron vuelta su fachadas y atrios-, ambas dejaron testimonios materiales de sus épocas precedentes como una manera de evidenciar su larga historia, pero la iglesia católica iría generando en su alrededor la Plaza Mayor, la casa de gobierno enfrente, los grandes edificios del poder político y social, con lo que crecería en lujos y majestuosidad. La capilla solo logró sobrevivir aprovechando coyunturas políticas liberales en los momentos en que la presencia afro fue considerada útil con el caos de las guerras.
El inicio de la construcción de la gran iglesia de San Miguel al lado de la capilla fue el principio del final, no se demolió la antigua pero sí se la arrinconó (Fig. 4). Pese a eso, fue modificándose, adaptando nuevos sincretismos afro-católicos, perdiendo tradiciones, generando hibridaciones en que incorporó todo lo que le fuera útil para subsistir. Hubo incluso adaptaciones de experiencias arquitectónicas hechas por o para los pobladores indígenas incluso de lejanos territorios, todo fue útil para llegar hasta el final del siglo XIX mientras su entorno cambiaba. Finalmente, la reducción cuantitativa de los pobladores afros, el incremento del valor de la tierra que los hizo trasladarse hacia otras zonas, las nuevas avenidas, el reordenamiento urbano y la inauguración de la aledaña gran iglesia acabaron con su historia.
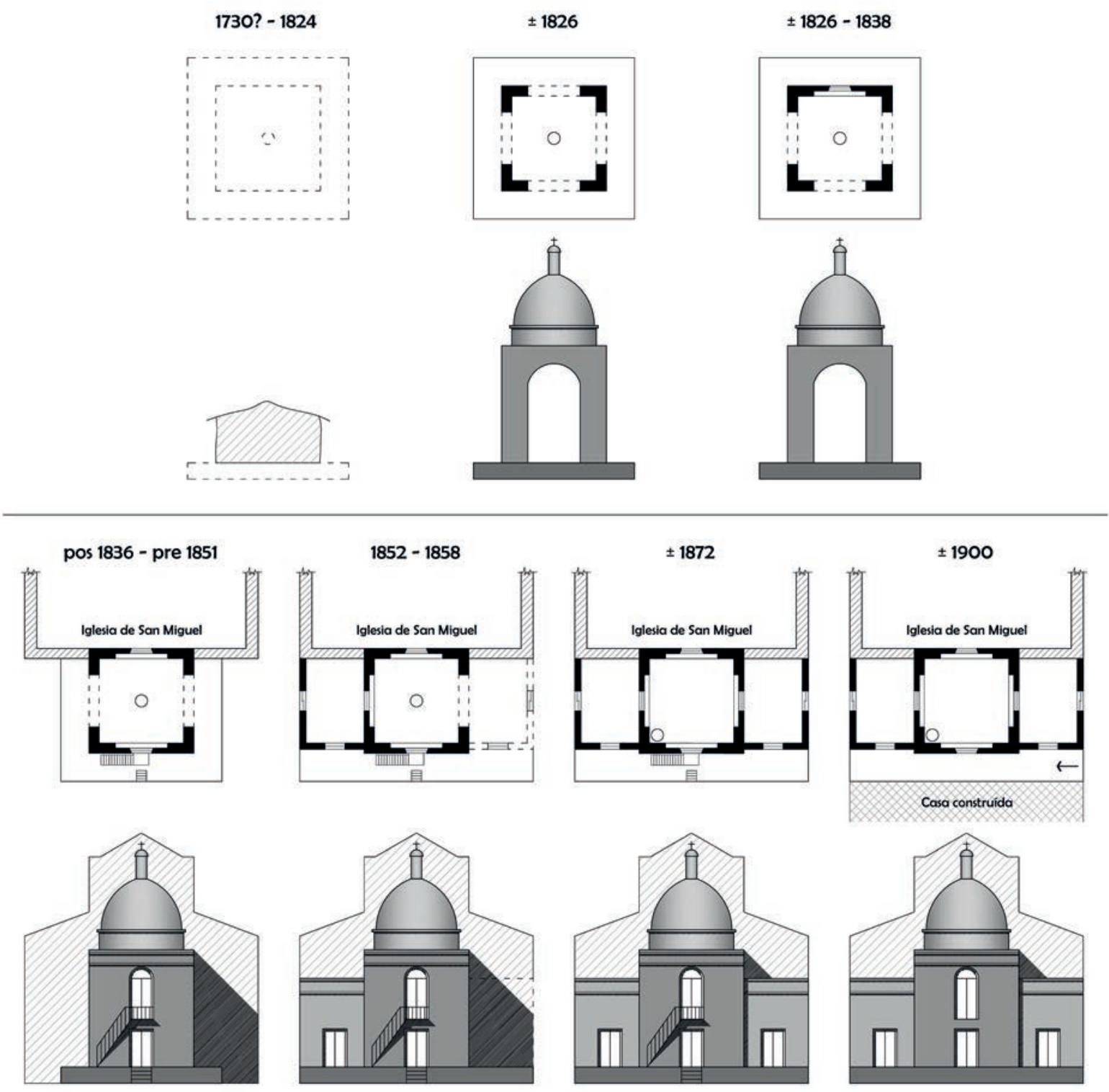

Figura 4. Reconstrucción del posible proceso de transformación de la capilla y sus fechas. Dibujo: F. Chechi. 
Usamos la palabra híbrida como referente a "algo que es producto de elementos de distinta naturaleza", en su acepción reconocida. Porque no fue una construcción que solo siguiera pautas de la memoria africana, o de experiencias emancipadoras, sino simplemente fue el resultado de aplicar ideas preexistentes de la época colonial y de otras que venían desde el universo de lo usado para los indígenas amoldado a sus necesidades, a la ritualidad católica. Fue la suma y transformación de todo lo posible en la medida en que era factible hacerlo. A la capilla le tocó la época de cambios que llevó a la libertad, pero también a su desintegración como comunidad.

\section{EL CONOCIMIENTO DE LO AFRO EN ARGENTINA}

La historia, más allá de los racismos de cada momento, ya desde el inicio del siglo XX produjo libros sobre la esclavitud y la población afroargentina (Rossi 1958 [1926]; Kordon 1938; Lanuza 1942). Es cierto que esos libros quedaron olvidados por no ser políticamente correctos y hasta cerca de la década de 1950 no comenzaron las publicaciones profesionales (Molinari 1944; Rodríguez Molas 1957; Studer 1958; Ortiz Oderigo 1969). Luego fueron años que oscilaron entre dictadura y democracia y eso produjo pocos estudios, tanto nacionales (Golberg 1976; Cejas Minut y Pieroni 1998; Picotti 1998) como en el exterior (Andrews 1980; Lewis 1984). Con los años la historia fue avanzando hasta lograr un boom con el ingreso al siglo XXI y las luchas por los derechos civiles de las minorías, con lo que se logró que quedara establecido el tema como campo de la política de estudio, de enseñanza y de enfrentamiento a la tradición historiográfica (Frigerio 1993, 2006; Geler 2010).

La arqueología en cambio tuvo una fuerte falta de visión sobre la población afro. El primer estudio específico se hizo en 1995 (Schávelzon 2001, 2002). Nuestro libro del año 2003 (Schávelzon 2003) identificó objetos y lugares (Coloca y Orsi 2013; Stadler 2015; Zorzi 2015; Richard 2019), se pudo ubicar los mercados de esclavos y se logró encontrar en la iconografía y los documentos imágenes y referencias a los espacios físicos de la africanidad (Schávelzon 2003, 2010, 2013). En esos años la antropología comenzó también a avanzar encontrando que había lugares, ritualidades y objetos mantenidos en silencio, ya no en los documentos sino como registro material (Cirio 2004; Coloca y Orsi 2013).
Si bien se ha comenzado la primera excavación de un quilombo (Richard 2019), hasta ahora solo ha habido excavaciones de sectores que ocuparon en viviendas de alto rango, o hallazgos de casualidad (Stadler 2015). La arqueología tradicional ha establecido que esta no es más que una arqueología de la pobreza, lo que solo en parte es cierto (Frigerio 2008), porque niega la complejidad de un grupo social desplazado y marginal, pero a la vez, minoritariamente, a ser propietario de viviendas y a tener sus propios esclavos (Rosal 2001). A su vez la sociedad blanca adoptó rasgos culturales afros aun presentes en la sociedad actual: el tango, el bombo y decenas de palabras en el lenguaje cotidiano. Se invisibilizó el mundo afro, se lo hizo desaparecer a medida que la gran inmigración blanca reducía su volumen porcentual, pero está presente. Pese a eso, la idea de una historia sin presencia afro logró permearse en el imaginario colectivo a través de la educación pública y la historia oficial, hasta la actualidad en que "no se puede ser negra y argentina a la vez"2. Se construyó un pasado basado en rechazar los méritos de la interetnicidad, a diferencia de otros países en que se los ensalzó para construir mitologías nacionalistas.

\section{LA POSIBLE HISTORIA AFRO DE LA CAPILLA DE SAN MIGUEL EN PARANÁ}

La capilla de San Miguel Arcángel, vista hoy, es una estructura atípica como arquitectura religiosa regional de la que no existen planos originales, ni fecha de erección, ni atribución a su constructor, pese a que es una obra importante para su tiempo. Esta falta de datos ha sido considerada extraña, es más, casi imposible de haber sido construida en esa época ya que no había quien la proyectase (Gutiérrez, De Paula y Viñuales 1971). Esto es cierto si se la mira como una obra hecha de una vez, fruto de un proyecto de un arquitecto y no como el resultado de un siglo de alteraciones, aditamentos y cambios de forma y función sobre una estructura de tradición colonial española de funcionalidad indígena (Fig. 5). No fue fruto de la creación de alguien, fue el resultado de agregar y quitar por manos anónimas, las que hicieron lo mejor que se pudo en cada época.

La historia tradicional adjudica haber sido iniciada la obra en la década de 1820 pero creemos que su estructura central es anterior. En esos años en la región recién comenzaban a llegar constructores avezados, generalmente

\footnotetext{
Nota periodística del 24-8-2014, Clarín, portada.
} 
italianos, y el estilo ornamental que sobrevivió en es neoclásico, el que apenas se iniciaba en la zona. Es una obra demasiado moderna para su época si la pensamos completa en 1823 o 1824 como se ha creído. Una obra imposible con la realidad material de la época.

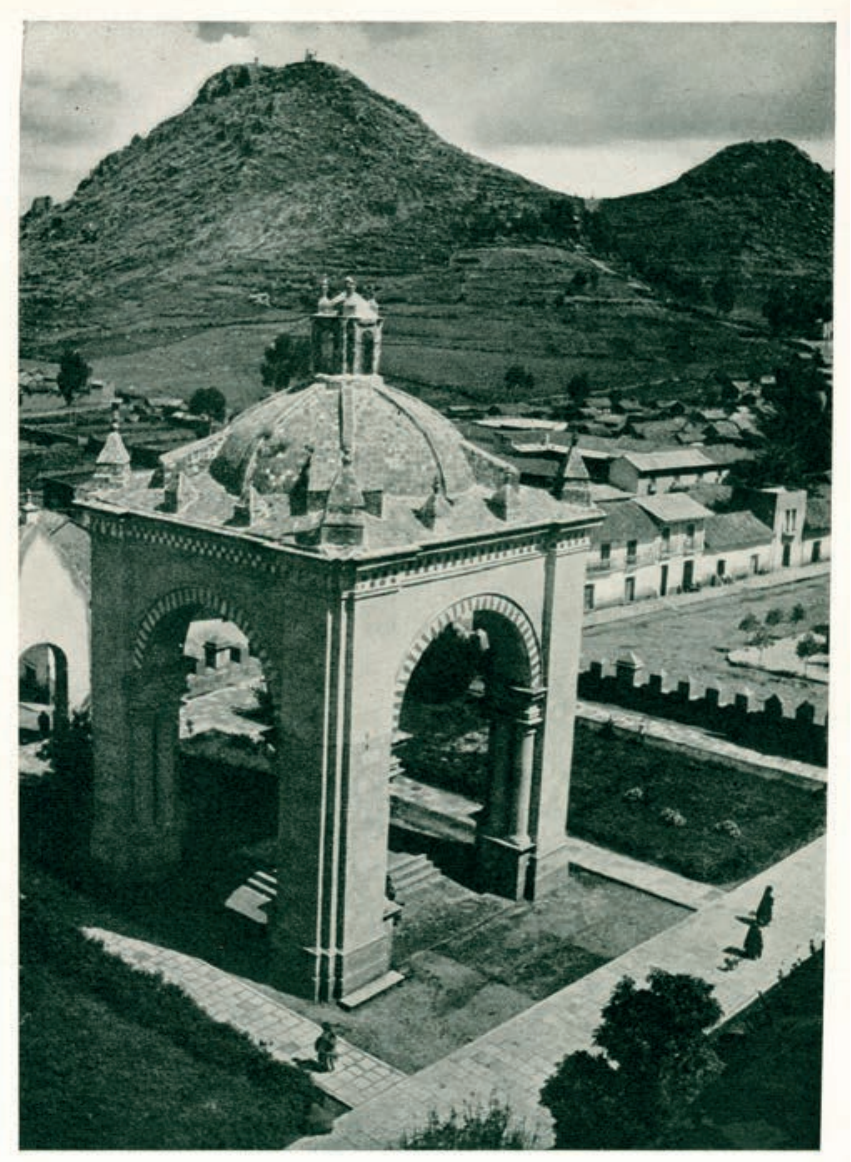

Figura 5. Capilla abierta de la iglesia de Copacabana, Bolivia. Fuente: Noel 1950: lam. 50.

La capilla hoy está compuesta por un volumen acupulado central, de planta cuadrada, y dos habitaciones a sus lados, todo sobre un basamento. La cúpula sobre el cubo central mide unos siete metros de diámetro. En cambio, los dos bloques laterales están techados con el sistema de terraza sobre vigas de madera y enladrillado, costumbre difundida en la zona una generación después. El interior es hoy de un clasicismo que no coincide con los tiempos en que se postula que fue construida, ni los ornamentos, ni las puertas y ventanas (que las obras mostraron haber tenido otra ubicación), ni la carpintería de una peculiar puerta-ventana de estilo neogótico ubicada sobre la entrada (Figs. 1 y 2). No resulta lógica la versión de una obra hecha de una vez y la evidencia arqueológica lo ha probado.
Por lo que hemos descubierto el piso fue de ladrillos y los muros eran blanqueados sin revoques (enlucidos), no hubo altar y se halló una puerta tapiada en dónde hubiera podido haber estado según la tradición. Las construcciones anexas - casa cural y sacristía- tuvieron modestos pisos de tierra y sus muros, ventanas y puertas muestran ser de fines del siglo XIX. Es decir, que al menos en decoración y circulación toda, menos la estructura central, fue diferente a lo actual.

El espacio central, aunque impresionante por su altura, era chico y no podía contener cien personas paradas y apretadas, y si para oír misa las mujeres se sentaban en el piso como era costumbre, y los ancianos en una silla, es difícil que entraran cincuenta personas. En síntesis, o era de ritual católico tradicional pero para una comunidad muy reducida o la forma en que se organizaba su interior y exterior era diferente y por ende para una ritualidad no católica. Por esto es que planteamos una funcionalidad diferente y gracias al hallazgo de un pozo en el centro que en origen pudo tener el poste ritual habitual en las capillas afroargentinas, luego reusado para una pila de agua bendita. El espacio reducido interior solo servía para albergar al Rey y la Reina y las autoridades en sus tronos como en otras estructuras similares de la región, la gente circulaba y no se detenía y raramente habría misas en el sentido tradicional. No hay evidencias ni lugar para un altar, para el coro, el presbiterio, o para un púlpito, todos hechos extraños si era católica. En una excavación se encontró un pozo para recibir agua en un rincón, lugar lógico para una pila bautismal pero que había roto el piso de ladrillos por lo que debió ser un evento tardío. Todo nos habla de cambios, de una fuerte reconversión funcional.

En forma sintética creemos que para el siglo XVIII existió un rancho de adobe y paja sobre un basamento, el cual fue demolido en la década de 1820 (o quizás antes) para construir en estilo colonial (o "poscolonial" como lo llamaron algunos historiadores), una capilla abierta o miserere con cuatro pilares con una cúpula, una doble puerta al sur y un terreno frontal abierto que servía de atrio. Como único adorno sobre los muros blanqueados pero sin revoques, resaltaba su enorme cúpula y una moldura saliente. Suponemos en base a la evidencia que desde el inicio estaba abierta hacia los cuatro lados, o quizás solo dos. Y que para la década de 1820 tuvo grandes cambios y eso es lo que se usó más tarde para decir que fue construida en esos años olvidando los orígenes. Tan grandes fueron estas obras para la pequeña ciudad cercana, tan impactantes en relación con la catedral en 
eternas obras, que en menos de diez años se inició la iglesia aledaña unida por el lado sur, en donde estaba el atrio, destruyéndolo y modificando su fachada y acceso. Simplemente la dieron vuelta para que quedara la nueva obra mirando a la ciudad que crecía cada día y la capilla quedase tapada y en sombra (Fig. 6).

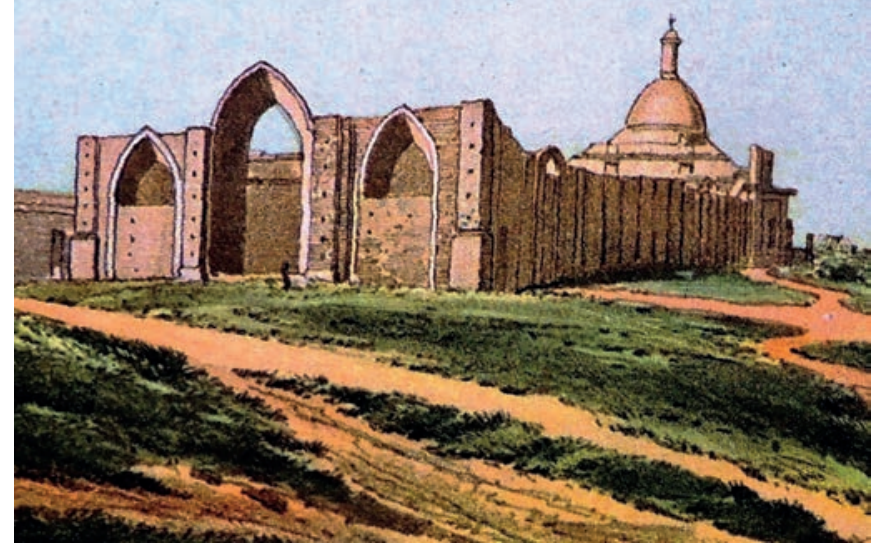

Figura 6. Vista de la capilla en la parte posterior de la nueva iglesia en construcción en 1858, ilustrada por Anton Goering. Fuente: Burmeister 1946, vol. II, s/pag.

La gran iglesia que la aplastó literalmente la transformó de forma brutal a la vez que comenzó el proceso de hacer iglesia a la capilla, ya en un contexto político conservador, con su nueva puerta y atrio hacia el norte. Haber obligado a dar vuelta la fachada y el atrio no fue poca cosa, pero quizás simultáneamente se hizo la casa cural a su lado, y la sacristía llegó veinte años más tarde para hacer más o menos simétrico al conjunto. Pero se resolvió el problema de esos cambios agresivos haciendo una ventana-balcón a la que se accedía desde el exterior, lo opuesto a un coro, con una ventana externa encima de la puerta. De esa forma se podía decir misa o hacer los rituales establecidos para la época, hacia la población reunida en el nuevo atrio. Había pocos antecedentes de ese sistema funcional en la región, pero existen; incluso la catedral había sido dada vuelta en 1818 para mirar hacia el interior del territorio y no al río. En realidad, la capilla usó una solución híbrida, inusitada, que desapareció hacia 1900 y se consolidó en la actualidad porque no buscó los orígenes o las contradicciones sino el estado actual, la simetría y lo que debía ser para mostrarse realmente como una capilla.

\section{LA CONSTRUCCIÓN DE LA HISTORIA Y LAS OBRAS}

La historia de esta construcción y la explicación de su construcción y cambios, se cruzan con la de la política de la ciudad y de la provincia, con la capacidad de la población afro de negociar con las autoridades. Eso es lo que nos permite entender los altibajos de una obra poco habitual que expresa la evidencia material.

Para hacer una historia mirada desde el universo afro tenemos que remontarnos a los orígenes, a un asentamiento sin trazado, que parecería centrípeto y no cuadricular, del que aún quedan resabios en calles recortadas y callejones radiales inexplicables. Fue difícil el diálogo con la ciudad criolla creciendo -y expandiéndose- en sus cercanías ya que en realidad estaban sobre dos morros o pequeñas elevaciones separadas por un pantano formado por las lluvias, lo que era muy simple de modificar. Por eso el trazado tradicional español de la nueva ciudad, la reorientación de la catedral y la ubicación de los edificios principales chocó no solo con el barrio sino con el hecho de que la llegada desde el puerto era arribando a la capilla de la población negra. Aunque se quisiera hacer toda la ciudad a nuevo, la realidad lo hacía complejo, al grado que fue necesario hacer una alameda de llegada, levantar la iglesia de San Miguel junto a la capilla, construir una plaza que la enfrentara y le diera escala monumental y se trazaron nuevas manzanas; pero la impronta original fue difícil de borrar. Hubo que esperar un siglo para lograr un puerto nuevo y un acceso directo que dejara de lado las zonas antiguas, pero cuando se lo hizo ya nadie se acordaba siquiera que antes había sido diferente.

La existencia misma de este conflicto, la capilla antigua que allí seguía, los pobladores -ahora más pobres que afros-, los que aun vivían en la zona y la memoria arraigada, hizo necesario en la segunda mitad del siglo XIX que además de cambios físicos se iniciara la construcción de una historia que podemos llamar oficial, que borrara los resabios del pasado no deseado. Esa nueva historia nos dijo que al iniciarse la segunda etapa de la catedral, un párroco recién arribado a la ciudad recibió un problema: se suponía que la advocación debería ser a la Virgen del Rosario, pero se la atribuía a dos santos adorados por la comunidad afro-criolla: San Miguel y Santa Rosa de Lima. Eso generaba agrios conflictos socio-raciales. La historia asevera que ahí fue cuando se inició la historia de la capilla de San Miguel, apropiándose de lo preexistente. 
Era posible hacer una historia nueva y los historiadores tenían con qué: para esos años de la década de 1820 el territorio estuvo en una situación convulsa de revoluciones a diario, el conflicto socio-racial se hacía presente y la advocación a la virgen de la catedral, donde la comunidad blanca-criolla quería a la suya, fue lo que permitió justificar una enorme construcción histórica (Pérez Colman 1930; Calvento 1939-1940; Reula 1963). Lo que se contó es que para la resolución del conflicto se hizo una votación pública acorde al liberalismo imperante, lo que se usó como justificación de un primer ejercicio de democracia (interesante que la democracia electiva la iniciara la iglesia). Y obviamente ganó la Virgen del Rosario. En base a eso, se asevera, es que se decidió mudar a San Miguel a una nueva capilla. La iglesia se había apropiado del pasado como si la capilla no fuera preexistente. Incluso para algunos fue un acto de condescendencia.

Sea verdad o un simple manejo de la información, así se dice que comenzó la construcción y si hubo algo antes todo fue cristianizado aprovechando la situación (Pérez Colman 1946: 131). Por cierto, parece una hermosa construcción historiográfica. Tan simple que el primero que narró eso fue un historiador que no tuvo acceso a los documentos que lo probaban, los que solo habían sido vistos por otro colega, Benigno T. Martínez que publicó sobre ellos en 1920, sin reproducirlos. Ese primer historiador local (1816-1925) era de nacionalidad española, de ideología conservadora, ultra cristiano. Y como era obvio de esperar luego de él las actas del archivo se extraviaron. Por lo que todo esto es una historia que dista de estar demostrada y que no parece casual que sucedió -casualidad- el año en que las órdenes religiosas fueron prohibidas en la provincia.

¿Es posible que esto siquiera tuviera un atisbo de verdad? El viajero Hermann Burmeister en 1857 (1943) decía que la mayoría de los casi 6000 habitantes eran "gentes pobres y de color", pero si bien el poder estaba en la clase blanca/criolla la comunidad afro liberta había crecido como para presionar sobre las autoridades, más cuando era habitual que los políticos y militares se aprovecharan de ellos. Pero el país y el Estado habían cambiado desde la Independencia en su relación con la población afro. En esos años se habían liberalizado muchas tradiciones raciales y el gobierno de Bernardino Rivadavia en esa década tendió a una fuerte secularización llegando a expulsar órdenes religiosas, confiscando iglesias y conventos. En 1824 el gobernador Mansilla suprimió el diezmo en Paraná y poco después su sucesor
Sola lo hizo con las órdenes religiosas al igual que con sus conventos y propiedades. Fue ese espíritu liberal el que creemos que obligó a la Iglesia, en ese mismo año, a autorizar, financiar o al menos a no oponerse a la construcción de la capilla o la ampliación de lo que existía. En realidad, aunque fuesen los pilares y la cúpula, era ya una gran obra para la ciudad.

Pero la historia fue escrita después de la blanquización, y por los conservadores, por lo que quedó como que el cura Antolín Gil y Obligado decidió romper el conflicto de la advocación de la catedral creando $a$ nuevo una capilla en la zona pobre, afro por cierto. Una lucha de poderes y un enfrentamiento social y racial que determinaba el crecimiento de la propia ciudad, y que terminó siendo mostrada como un simple juego electoral y un acto de benevolencia cristiana.

Revisando la historia vemos que el trasfondo de esas obras era un panorama político complejo: tras las fracturas entre estados producto de la Independencia se desataron las luchas entre Unitarios y Federales dado que las provincias se autoproclamaron independientes. En lo que hoy es la provincia de Entre Ríos -cuya capital es Paraná-, el personaje central fue Francisco Ramírez, quien gobernó entre 1820 y 1821, estableció la República de Entre Ríos separada de lo que había sido el Virreinato del Río de la Plata o de las posteriores Provincias Unidas del Río de la Plata. Fue sucedido por Lucio N. Mansilla, un militar relacionado con los liberales de Buenos Aires, marcado progresista que suprimió las órdenes religiosas. Pero casi de inmediato las guerras cubrieron el territorio: entre 1824 y 1832 hubo trece gobiernos en Entre Ríos por lo que era imposible el avance edilicio. Los gobiernos Ramírez y Mansilla fueron una época adecuada para comenzar la capilla ya que hubo estabilidad y respeto institucional, pero en seguida todo cambió. Ramírez había escrito que "yo creo que cuantos menos (curas) haya seremos más felices" (Calvento 1939-1940, VIII: 476), y la gran obra de modificación de la capilla se hizo factible gracias a eso, a que era para la población marginada. Ni siquiera sabemos si alcanzaron a completar lo que se hubiera pensado hacer.

Respecto al edificio nos preguntamos cómo era lo que se hizo: ¿una capilla abierta al sur? (la actual mira al norte). ¿Era posible que estuviera abierta a dos lados o incluso a cuatro?, ¿que hubiera quedado algo anterior? No hay datos más allá de la arqueología sobre un posible precedente, pero la primera obra debió ser una cúpula sostenida por cuatro grandes pilares a la usanza de otras capillas abiertas (o misereres), cuyo máximo ejemplo es 
la de Copacabana en Bolivia. La mejor evidencia de que hubo un primer atrio al sur y que fue destruido por la nueva iglesia hacia 1833 es el haber encontrado el marco de las puertas aun empotrado (Fig. 7). En eso estamos seguros; pero si la puerta del norte ya existía, o incluso si eran cuatro, es algo imposible de saberlo. Es decir, estuvo abierta al sur, y quizás a la vez y desde siempre también al norte, como ahora. Respecto a los otros dos lados (este y oeste), si bien las evidencias históricas y arqueológicas indican que la casa cural y la sacristía que hoy existen en sendos lados son de las décadas de 1830 y 1850 , la estructura original bien pudo estar abierta también en esos lados. La excavación de un cimiento parecería mostrar eso, pero es poca evidencia para una hipótesis tan fuerte.

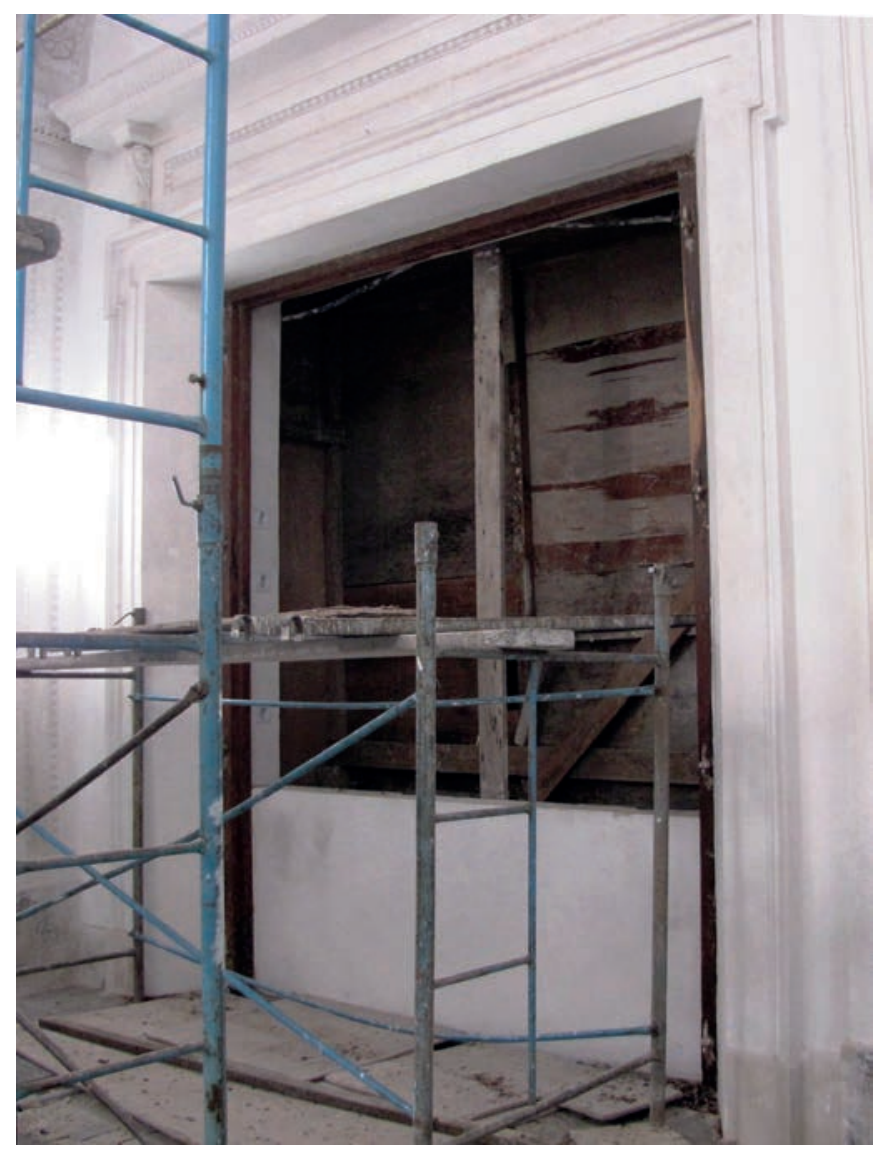

Figura 7. Puerta descubierta empotrada en la pared que correspondería al altar, que indica que en origen la capilla estaba orientada hacia el lado opuesto al actual. Fotografía: Daniel Schávelzon.

En 1831 todo el avance liberal cambió cuando llegó al poder local Pascual Echague, quien estuvo aferrado a él por diez años; era un católico ultra conservador que restableció el diezmo colonial, autorizó el regreso de los expulsos jesuitas, impuso la enseñanza de la teología, anuló la legislación progresista y se hizo llamar "Ilustre restaurador del sosiego público". Fue solamente otro dictador más, glorificado por los historiadores conservadores por haber hecho grandes donaciones a la iglesia. Y la construcción de la iglesia de San Miguel fue obra de ese gobierno, con la insólita decisión de unirla con la preexistente por sus espaldas y hasta con el mismo nombre, para desdibujar la antigua. Y si no la demolió fue porque pensó en usarla durante las obras y luego incorporarla; y de eso sí hay evidencia arqueológica en las uniones de los muros y cimientos del lado oeste al menos.

Pero la historia le sería cruel también a la obra de la nueva iglesia y su intención de borrar la capilla, porque el país cambiaba más rápido que las grandes construcciones. Echague en su gobierno trazó además la reurbanización de la zona, se hizo una nueva plaza y la Alameda, que era la vieja calle que unía la ciudad con el puerto, pero sin cambiar los puntos neurálgicos. Una hipótesis similar a la nuestra en cuanto a los cambios urbanos para dar una nueva imagen a la ciudad la dieron en forma difusa el historiador Pérez Colman (1937: 5758), al analizar el trazado de la zona, sus lotes y apertura de calles y la historia de la capilla y la iglesia. Dijo que era adecuada "la suposición de que la primitiva capilla edificada que actualmente se conserva detrás del altar mayor de la iglesia, debió construirse con su frente a la calle San Miguel", es decir con otra fachada (Pérez Colman 1946 57). Quienes construían la historia también dudaban. El reordenamiento municipal que se hizo en la zona se logró con compras y permutas de terrenos, demoliciones de casas, apertura de la avenida, el amanzanamiento, la nueva plaza, y más que nada con la gran iglesia de San Miguel. Todo fue una hábil decisión de política urbana.

Y si bien y pese a todo la vieja capilla era lo primero que el viajero veía al llegar, a donde se subía desde el puerto, para 1833 comenzó a ser borrada por la iglesia en construcción y el planeamiento urbano parece haber sido parte del proyecto político-ideológico de reordenar la primera parte de la ciudad. Y por eso los primeros documentos que hablan de que el espacio del atrio pasó a ser propiedad particular son de 1838 , aunque nadie lo ocupara realmente por un siglo (Ceruti 2007: 391).

Es aventurado pensar en que hubo un plan para reubicar a la población afro sacándola del Barrio del Tambor con la nueva urbanización, pero sí es posible ver una serie de donaciones y ventas de tierras hechas por la Iglesia a muy bajo precio, cuando el municipio comenzó 
a amanzanar la zona interesado en que esas modestas viviendas tuvieran lo que para ellos era la apariencia urbana y que se delimitara la plaza. El ordenamiento urbano y las obras ejecutadas fueron actos que marcaron el dominio de las tierras y la capacidad del estado de comprar, demoler y ordenar (Dócola 2017; Mazzitelli Mastricchio 2018). La gran iglesia de San Miguel no se inauguraría hasta la década de 1870 , dejando inactiva la capilla vieja, en una ciudad que aparentaba al menos haber sido hecha a nuevo.

Los documentos originales son claves en esta historia ya que varios historiadores se refieren a ellos, pero pocos dan datos concretos. El manuscrito que ha sido atribuido a la historia de la capilla no dice nada de todo lo aseverado en docenas de libros, porque la portada ha sido alterada por alguien que le sobrescribió "San Miguel 18?1", en donde las hojas tienen la numeración original tachada y fue vuelto a numerar. En realidad la mayor parte del texto y pese al título de tapa, es sobre la construcción de la catedral y no de la capilla, lo que llevó a muchas confusiones. Al final hay unas páginas posteriores a 1871 de la aledaña iglesia de San Miguel, sobre su inauguración y primeros eventos para juntar fondos ${ }^{3}$.

Tras la caída del gobernador Echague en 1841 hubo otros seis gobiernos en trece años, hasta que Justo José de Urquiza tomó el poder y siguió en él hasta derrocar a Juan Manuel de Rosas en Buenos Aires, hacer la Constitución Nacional y crear la Confederación Argentina en 1853, con la capital del país en Paraná. Con él comenzaron a construirse edificios públicos y a crecer la zona céntrica; la libertad de los esclavos quedó establecida y el tema racial minimizado. Con nueva estabilidad económica y la política liberal, la capilla tomó su forma definitiva, con dos cuartos -sacristía y casa cural-, a ambos lados. Así es como se la ve en la litografía de Anton Goering de 1858 publicada por Burmeister. Existe un detalle arqueológico que comprueba que esas estructuras adosadas no son originales y es que el piso no coincide con el central ni es de ladrillos, y que las puertas y ventanas no eran simétricas, aunque ahora desde afuera así se vean, pero en el interior se hace evidente la falta de un proyecto conjunto. Incluso la altura de los techos de las áreas anexas fue decidida en la restauración para acentuar la simetría, pero que no era así y la evidencia material era visible.

\footnotetext{
3 Libro de entrada de las limosnas para la iglesia nueva. San Miguel. Paraná. Sección Hacienda, Fondo Asuntos Eclesiásticos 1822-1874, no. 983, Archivo de la provincia de Entre Ríos.
}

En la imagen de la capilla publicada en 1874 se ve el conjunto ya consolidado tras los cambios mayores, con sus dos ambientes laterales construidos, una escalera al frente con puerta y una ventana-balcón y con el atrio abierto (Fig. 1). La ventana-balcón tiene el mismo tipo de cerramiento y bisagras que la aledaña iglesia, incluso la misma decoración neogótica, lo que habla de su época de construcción que no fue la original. Lo que se veía para ese momento era el resultado de medio siglo de adaptaciones y cambios, del intercambio entre la ritualidad original y la catolización del edificio.

Hay detalles constructivos que remarcan esos cambios pasada la mitad del siglo XIX: la citada modificación de las puertas y ventanas a un nuevo estilo, el uso de baldosas francesas, las bisagras de las puertas y su hechura, las rejas que no coinciden con las ventanas, entre tantos detalles. Hay evidencias de que hubo tiempos sin puertas internas y las que hay son de la década de 1880. La excavación de un sector de ambas construcciones laterales mostró la sola presencia de objetos del siglo XIX tardío e inicios del XX, a diferencia del interior del núcleo central que todo era un siglo más antiguo.

Para la inauguración de la iglesia de San Miguel en la década de 1870 , la capilla debía haber seguido funcionando para la población afro que aun quedaba viviendo allí ya adaptada a nuevos rituales. Si la historia que presentamos es verdadera, la capilla funcionó con la escalera frontal y el altar exento entre los años 1830 a 1900. Velozmente la ciudad había cambiado, la población afro se había reducido en porcentual y el Barrio del Tambor se había desdibujado; por eso en 1904 se hizo una casa en el atrio (Ceruti 2007) -ya nadie debía usarlo-, dejando como acceso a la capilla un simple corredor que no se veía desde la calle.

\section{ARQUITECTURA Y POBLACIÓN ESCLAVIZADA EN LA ARGENTINA}

Los estudios de las construcciones relacionadas con la población afro-argentina llevaron a establecer grupos de ellas: 1) las hechas para ellos, como son los mercados, lugares de carimbado (marcado a fuego), habitaciones en residencias privadas, las rancherías en que vivían dentro de los conventos, los obrajes y sitios de trabajo, y las capillas o sectores dentro de las iglesias (Schávelzon 2003); 2) la arquitectura generada por la población afro: sus viviendas y los lugares públicos, abiertos o cerrados, para bailar y reunirse llamados tango o nación. De estas 
queda solo una del siglo XIX, en Chascomús, pero por suerte también hay imágenes de sitios diversos (Ghidoli 2016), y varias capillas modernas que están siendo relevadas (Cirio 2002).

Existe un texto sobre el barrio afro de Buenos Aires que analiza viviendas de fines del siglo XVIII pertenecientes a esclavos y libertos (Rosal 2001), mostrando que no hubo un patrón residencial para quienes lograban la libertad o un ascenso social y la posibilidad de salir del gueto, y que algunos se dispersaban por la ciudad. La aspiración parecería ser llegar a tener las mismas casas que los demás, es decir el blanqueamiento. En una vivienda excavada que fue propiedad de un "pardo" por unos años, solo se le puede atribuir haberla adaptado a lo habitual (Schávelzon 1995). Lo que vemos en la cultura material mueble como persistencias, raramente lo vemos en la vivienda, pero sí lo vemos en la arquitectura religiosa y comunitaria.

En el caso de la ritualidad es donde es más fácil ver lo híbrido, lo multifacético de ese universo que se estaba generando en los inicios del siglo XIX cuando esclavizados y libertos se enfrentaron a un mundo libre pero con el que había que negociar todo, a la relación conflictiva con la sociedad dominante. Llegaban a un nuevo proceso que llevó al blanqueamiento y a un tipo de destrucción de la identidad muy diferente a la época colonial: la educación, la integración, las masacres en las guerras y el desdibujo censal.

La comunidad afro desde los finales del siglo XVIII comenzó a organizarse en naciones, agrupaciones que se formaban por afinidades lingüísticas, también llamados tangos - palabra que llegó a la actualidad para un tipo de música y baile-, y esa fue la manera cívica de reemplazar las cofradías religiosas como núcleo de cohesión, con libertad para bailes, ceremonias y rituales. Hubo más de doscientas en Buenos Aires y a lo largo del tiempo terminaron transformados en clubes sociales y asociaciones (Platero 2004; Cirio 2009). Eran comunidades cerradas que obedecían a un rey y una reina, con sus tronos, cetros y jerarquías, reproduciendo el sistema colonial (Rossi 1958). Hay fotografías de esos reyes en 1910 viviendo en extrema pobreza pero manteniendo la tradición del baile y la música con tambores (Soiza Reilly 1905). Aún existen esos lugares que reproducen la jerarquía tradicional (Cirio 2002). Existe un cuadro del pintor Martín Boneo de la década de 1830 que muestra uno de ellos funcionando en la parte exterior de un rancho en Buenos Aires, en donde hay un baile en homenaje al gobernador (Fig. 8). En las iglesias o sus cercanías, en tiempos previos, el tema había sido muy complejo porque se usaban los atrios o terrenos baldíos: "como es ponerse en el atrio del templo a danzar los bailes obscenos que acostumbran, como ejecutaron el día de San Baltasar a la tarde y el domingo de Pascua", en 1789 (Acuerdos del Honorable Cabildo de Buenos Aires... 1938, 3 (8): 628).

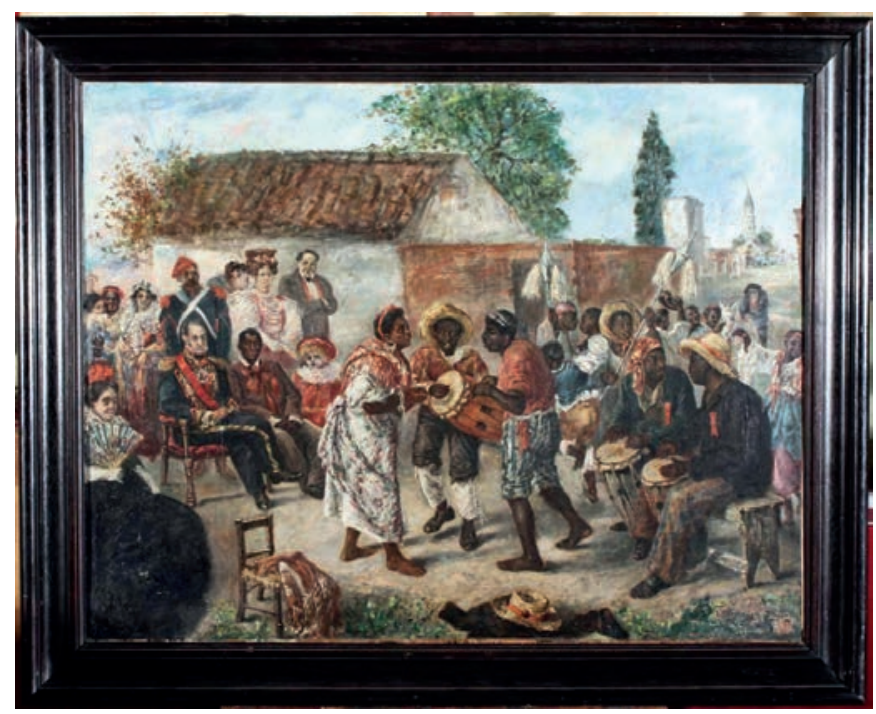

Figura 8. Vista de un Tango de una comunidad afro pintado por Martín Boneo en 1835, con la visita del gobernador a un baile en la parte exterior. Fuente: Museo Histórico Nacional.

Como citamos, la única construcción del siglo XIX que aun existe, aunque alterada, es la Sede de la Nación Beyombé de Invenza en la ciudad de Chascomús. En 1861 una "nueva hermandad de morenos" solicitó hacer un "Cuarto de las Ánimas y demás objetos indispensables para nuestro regocijo", lo que les fue permitido hacer en un lote fuera de la ciudad. El edificio es un rectángulo con una fachada tradicional, el piso es de tierra y el techo fue de ramas. Pero en la parte posterior debió haber otra fachada ahora en gran parte cubierta. En 1960 se hizo una reconstrucción del edificio transformando el lugar en una planta basilical para declararlo Monumento Nacional, cristianizado; el "Lugar de las ánimas" pasó a llamarse "Capilla de los negros". Queremos destacar que haya sido un espacio por el que se circulaba y que en su interior se bailaba. Se cuenta que "en el centro había un poste, con un tosco ídolo tallado en la cúspide" (De Isusi 1953). Esos "postes rituales" parecen ser omnipresentes hasta la actualidad y han sido descritos en tres capillas no lejos de Paraná. A veces en el exterior, otras en el interior, pero en todos tienen un papel ritual, simbólico y tradicional. Esto parecería repetirse en otras 
regiones donde el poste es "el centro mágico del poder" (Cirio 2002: 98). Y es la mejor explicación para un agujero central en el piso de la capilla de Paraná, que si bien se creyó ser de una pila bautismal, una mirada diferente puede darle otro significado de origen luego alterado (Fig. 9).

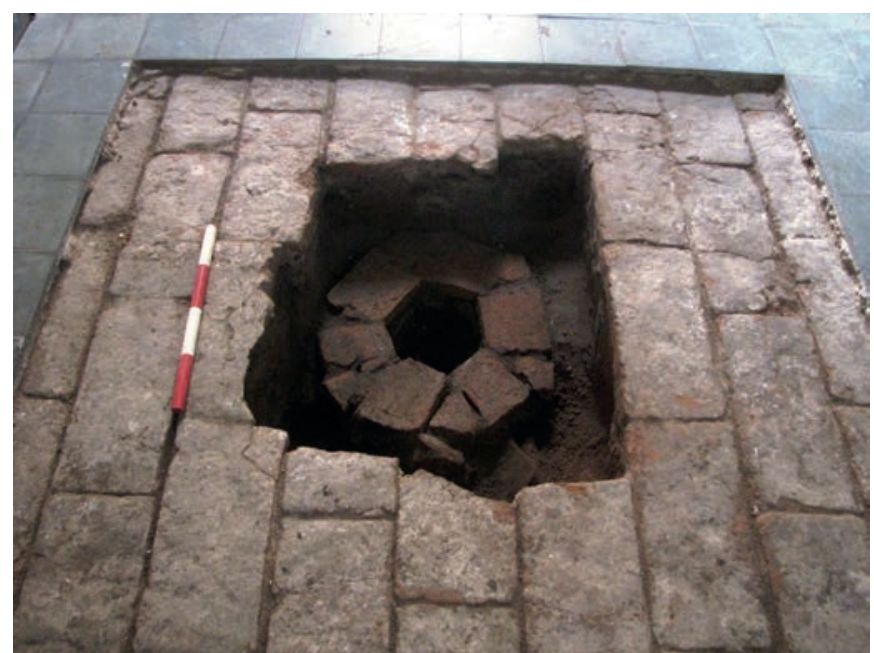

Figura 9. Excavación de un pozo de poca profundidad ubicado en el centro de la capilla. ¿Pila bautismal o poste ritual? Fotografía: Daniel Schávelzon.

\section{CAPILLAS PARA INDIOS Y CAPILLAS PARA AFROS EN AMÉRICA LATINA}

El estudio de la arquitectura colonial en América Latina llevó a identificar obras que fueron respuestas a nuevas realidades. Pese a eso, la arquitectura para iglesias usó la tipología basilical. Con las diferencias lógicas de las búsquedas estéticas, las posibilidades económicas y los materiales accesibles, lo que se hizo tuvo pocas variantes aunque la realidad local llevó a buscar soluciones adecuadas a un mundo diferente; una cosa era la imposición de un modelo, otra la recepción y otra la adecuación, es decir, la respuesta (Gutiérrez 1997).

Son conocidos los aportes americanos a la arquitectura religiosa católica aunque hubieran precedentes europeos: los atrios cerrados, las capillas abiertas, las capillas-posa, las cruces atriales, los arco-cobijo, los templos-fortaleza, las capillas miserere o los ábsides con naves de muros bajos o sin ellos. Todo esto fue visto por los historiadores como producto de un cruce de culturas. En una de las grandes síntesis de la arquitectura de México, George Kubler dijo que eran la contribución: “más original al repertorio mundial de las formas arquitectónicas especializadas" (1948: 383); una frase no menor, pero que seguía siendo una mirada desde Occidente. Pero, ¿por qué nunca se imaginó que pudo suceder lo mismo con la población esclavizada? Quizás fue porque la comprensión de la fuerza de la identidad afroamericana llegó tarde, junto a las luchas por los Derechos Humanos. Y en Argentina comenzó a ser estudiado en la arqueología al fin del siglo XX (Schávelzon y Zorzi 2014).

La invasión del continente americano por Europa produjo la necesidad de catequizar y oficiar misa a masas de indígenas sin tener los lugares físicos que la doctrina indicaba: en el siglo XVI las primeras iglesias estaban en obra -con mano de obra indígena y esclava-, y la población blanca y criolla rechazaba compartir esos lugares en que la ritualidad heredada de España otorgaba sitios de privilegio para cada familia. Era por lo tanto necesario inventar, o encontrar modelos en la historia a los que acudir para lograr espacios físicos que sin alejarse de la doctrina pudieran resolver el problema. Europa tenía precedentes: capillas abiertas, púlpitos techados, galerías exteriores, balcones, capillas semiabiertas, porterías amplias, balcones y diferentes arquitecturas que fueron usados en América. La reminiscencia a las mezquitas no puede ponerse en duda, pero no tenemos aún noticias de lo que sucedía con los esclavizados en relación con el culto católico, ya que eran minoría ante la población indígena en esos lugares.

El observar estas capillas comenzó en México a inicios del siglo XX (Baxter 1901; García Granados 1935; Kubler 1948; Mac Andrew 1965). Mario Buschiazzo en 1939 planteó que también las había en Sudamérica y para 1953 se había entendido que América resultaba ser una amalgama de tradiciones y de nuevas necesidades que nacieron en el entrecruce de lo cristiano, lo musulmán y el empirismo de la conquista (Palm 1953). Pero tomemos en cuenta que cuando se cerraba el estudio de las capillas abiertas en México recién se iniciaba en Sudamérica. Los primeros en encontrar capillas abiertas en lo que fuera el Virreinato del Perú -al que pertenecía la actual Argentina-, en ese caso en Bolivia, fueron José de Mesa y Teresa Gisbert al observar las de Copacabana, donde los ejemplos son los que más se asemejan a la capilla en Paraná (De Mesa y Gisbert 1961, 1962; Noel 1950). Una de las capillas de ese conjunto también estaba cerrada por la iglesia a su espalda, tiene una bóveda de 63 metros cuadrados.

En forma reciente se ha encontrado evidencias de heterogeneidad en la supuesta homogeneidad de la arquitectura católica colonial Sudamericana. Ramón Gutiérrez 
ha compilado una lista de casos en Perú y Bolivia, mostrando que entre los finales del siglo XVIII e inicios del XIX hubo capillas para dar misa mirando hacia plazas y mercados, lugares que eran más atractivos para la población en domingo; y en Emboscada, Paraguay (Tardieu 2005), se lo hizo para la población afro-liberta desde un balcón en la fachada. Cita los casos peruanos de Catca en 1807, Urcos después de 1818, Huaro adaptándose a orquestas y fiestas, Sicuani en 1822 en la que se abría un ventanal desde el coro hacia el mercado colocándole un altar, Pucara con dos pisos para que la capilla fuese vista desde lejos y Vilque en que funcionaba en una feria ${ }^{4}$.

La experiencia de Paraná se inserta por lo tanto en un proceso de modernización que se estaba produciendo en Sudamérica de llevar el altar, las alocuciones y la misa al exterior de la iglesia. Si la solución de dar misa al aire libre desde un balcón se remonta a los inicios del cristianismo en América, y en el sur del continente siguió vigente hasta el siglo XIX, nada raro abría en encontrar casos en la Argentina. Incluso encontramos un ejemplo similar de escalera y balcón externos en la capilla de Santa Rosa en Guanacache, Mendoza, Argentina (Fig. 10). Era un poblado de indígenas muy denso en donde la iglesia fue modificada varias veces por los terremotos, siendo el último cambio de 1816. Tiene sobre la entrada un arco-cobijo, típica estructura sudamericana para proteger al visitante como si fuese una portería, y además posee un balcón con una escalera lateral que lleva a él. En ambos casos, Mendoza y Paraná, se podía usar el balcón estando la iglesia cerrada.

El tema de la arquitectura afroamericana sigue siendo un tema pendiente. Hubo avances en entender lo complejo de los procesos de hibridización, trasplante o incluso de permisividad patriarcal en la existencia de símbolos o espacios para la ritualidad afro. Desde que Gerardo Huseby en 1999 indicó que los relieves de músicos en la fachada de la iglesia de San Ignacio Miní, Argentina, tenían aportes africanos, hasta el estudio de Brendan Weaver (2018) que nos habla de los significados afroperuanos incluidos en fachadas coloniales, se avanzó lentamente. En todos esos casos vemos lo mismo: arquitecturas y estéticas sin precedentes locales que toman elementos de diferentes culturas, con distintos significados en origen, provenientes de regiones o grupos étnicos dispares, para satisfacer necesidades funcionales o simbólicas que no son las que los generaron, en gestos tanto de supervivencia como de resistencia.

\footnotetext{
4 Gutiérrez, R. 2017: Nuevas modalidadesde sacralización del espacio externo en el sur peruano. CEDODAL. Manuscrito inédito.
}

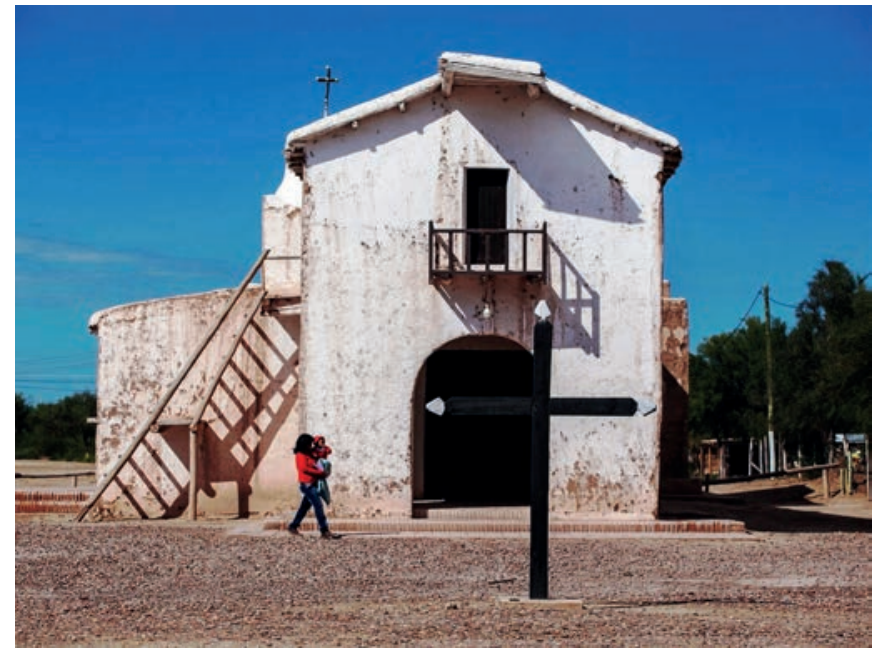

Figura 10. Iglesia de Nuestra Señora del Rosario en Guanacache, Mendoza, Argentina, con su balcón y acceso por escalera externa. Una capilla que apeló al mismo sistema de misa al exterior en atrio abierto. Fotografía: Archivo del Centro de Arqueología Urbana.

\section{CONCLUSIONES}

Este es un caso en que una sociedad afro tenía un espacio físico, una capilla, que resultó, con el tiempo, ser uno de los más significativos de lo que sería la ciudad de Paraná. El crecimiento de la sociedad blanca/criolla se produciría cerca, estableciendo un nuevo centro del pueblo, ubicando allí el gobierno y la catedral, disputando el significado de la capilla original. Esos conflictos llegaron a que para desdibujarla se construyera una enorme iglesia católica a su lado, pegada una a la otra, hasta llevar a la primera a su abandono y deformación física, para luego recuperarla con otra forma y significado. Fue un siglo, el de la emancipación de la esclavitud, en que la población afro fue blanqueada, minimizada, invisibilizada; que su arquitectura fue alterada y su ritualidad desaparecida. Es la historia de una confrontación y de las expresiones físicas que esta fue teniendo en el edificio hasta perder todo sentido.

Este estudio intenta, desde la arqueología, reconocer los elementos de esa historia, hacerla visible, repensar la arquitectura desde una mirada diferente a la tradicional, aunque sea altamente hipotética. Verlo en la arquitectura, así como la arqueología ha logrado reconocer elementos africanos $-\mathrm{o}$ reconstruidos en la Diáspora-, así como en la cerámica, la herrería, los entierros, la pintura mural, el uso del espacio, el color y en los objetos domésticos.

Lo que mostraron las excavaciones, la relectura de la historia documental y la observación del edificio, pese a las 
dificultades habidas por la alteración para su actual restauración, abrieron la posibilidad de entender un largo proceso de transformación vivido mientras servía a la población esclavizada y liberta. De una primera posible capilla abierta de la que no hay antecedentes locales, en medio siglo de enfrentarse a la iglesia oficial se llegó a una solución de dar misa desde un balcón, el que tuvo en su frente un gran atrio abierto y que nunca tuvo planta basilical. Y que en lugar de un altar es posible que haya tenido al centro un poste de carácter ceremonial, eje físico y simbólico de toda la construcción de planta cuadrada (Cirio 2002).

El cruce de los datos permitió entender la historia de esa construcción. Una historia que comenzó a mitad del siglo XVIII con una estructura modesta de adobe, luego una capilla abierta tradicional andina, más tarde los cambios profundos al comenzar otra iglesia en su frente y por ende una modificación sustancial en la manera de usarse, y la adaptación para sobrevivir generando una estructura híbrida pero eficiente. Al cerrarles partes de ella, cambiando su forma de circular y de usarla, se la transformó en iglesia, aunque no basilical -quizás parecida a un bautisterio-, en la que la misa se daba desde un balcón al atrio abierto. Vemos un proceso de respuesta, de adaptación y de resistencia. Los cambios finales con la destrucción del atrio y el hacerla casi inaccesible desde la calle terminaroncon su uso.

Quizás estemos mirando el proceso de catolización de la ritualidad afro en el siglo XIX. La capilla fue una estructura producto de diversas tradiciones constructivas, estéticas y funcionales, cambiante en el tiempo, expresión de la compleja identidad de un grupo social en plena transformación, del blanqueamiento y el desdibujo dentro de una sociedad blanca y cristiana. Es la expresión física de una lucha por sobrevivir, adaptándose, modificando, cambiando a veces sin cambiar, peleando, negociando muy fuerte para poder continuar, lo que lograron hacer por casi dos siglos.

\section{AGRADECIMIENTOS}

Alejandro Yonson, Walter Musich, Mariana Melhem y Gabriel Toranzo hicieron posible este estudio. A Ramón Gutiérrez le agradecemos el adelantarnos sus estudios. A Pablo Cirio por tanta información. A Patricia Frazzi, Alejandro Richard y Maximiliano Martínez que me acompañaron e hicieron el trabajo pesado, a Alejandro que buscó los documentos históricos en los archivos de Paraná y a Florencia Chechi que hizo los dibujos y reconstrucciones.

\section{BIBLIOGRAFÍA}

Aguirre, J. F. 1951: "Diario", Revista de la Biblioteca Nacional, III, p. 386. Andrews, G. R. 1980: Los Afro-Argentinos de Buenos Aires: 1800-1900. Ediciones de la Flor, Buenos Aires.

Baxter, S. 1901: Spanish-Colonial Architecture in Mexico. J. B. Millet, Boston.

Burmeister, H. 1943: Viaje por los Estados del Plata 1857-1860. Unión Germánica de la Argentina, Buenos Aires

Buschiazzo, M. 1939: "Las capillas abiertas para indios", Lasso (noviembre), s/n.

Calvento, M. 1939-1940: Estudios de historia de Entre Ríos. Imprenta de la Provincia, Paraná.

Cejas Minut, M. y Pieroni, M. 1994: "Mujeres en las Naciones Afroargentinas de Buenos Aires", América Negra, 8, pp. 133-145.

Ceruti, C. 2007: "Investigaciones histórico-arqueológicas en el entorno de la capilla vieja de San Miguel Arcángel, Paraná", en IV Congreso Nacional de Arqueología Argentina, I, pp. 385-393. Universidad Nacional de Rosario, Rosario.

Ceruti, C. 2010: "Los esclavos africanos en Santa Fe la Vieja”, en J. R. Bárcena y H. Chiavazza (eds.), Actas del XVII Congreso Nacional de Arqueología Argentina, III, pp. 1011-1016. Universidad Nacional de Cuyo, Mendoza.

Cirio, N. P. 2002: Africanismos y construcción de la tradición negra en las prácticas musicales del culto a San Baltazar en Argentina. Tesis de licenciatura, Facultad de Filosofía y Letras, Buenos Aires.

Cirio, N. P. 2004: "La desaparición del candombe argentino. Los muertos que vos matáis gozan de buena salud”, Música e Investigación, 12-13, pp. 181-202.

Cirio, N. P. 2009: Tinta negra en el gris del ayer: los afroporteños a través de sus periódicos entre 1873 y 1882. Teseo, Buenos Aires.

Coloca, F. y Orsi, J. P. 2013: "Las ciencias sociales y las construcciones culturales. Los grupos Afro de Buenos Aires y su visibilización/invisibilización desde la Arqueología Histórica", Kula. Antropólogos del Atlántico Sur, 8, pp. 15-27.

De Mesa, J. y Gisbert, T. 1961: "Iglesias con atrio y posa en Bolivia”, Anales de la Academia de Ciencias, 1, pp. 210-219.

De Mesa, J. y Gisbert, T. 1962: "Las capillas abiertas de Copacabana", Anales del Instituto de Arte Americano, 15, pp. 103-108.

De Isusi, A. 1953: La capilla de los Negros, una estampa de Chascomús. Editorial del Lago, Chascomús.

Dócola, Silvia 2017: Espacios de poder para la Confederación Argentina: la capital, el puerto y el lugar del soberano 1854-1859. Tesis de doctorado, Facultad de Arquitectura y Urbanismo, Universidad de La Plata.

Frigerio, A. 1993: "El Candombe Argentino: Crónica de una Muerte Anunciada", Revista de Investigaciones Folklóricas, 8, pp. 50-60.

Frigerio, A. 2006: "Negros y Blancos en Buenos Aires: Repensando nuestras categorías raciales", Temas de Patrimonio Cultural, 16, pp. 77-98.

Frigerio, A. 2008: “De la 'desaparición' de los negros a la reaparición de los afrodescendientes: comprendiendo la política de las identidades negras, las clasificaciones raciales y de su estudio en la Argentina", en G. Lechini (comp.), Los estudios afroamericanos y africanos en Latinoamérica: herencia, presencia y visiones del otro, pp. 117-144. Clacso, Buenos Aires.

García Granados, R. 1935: "Capillas de Indios en Nueva España”, Archivo Español de Arte y Arqueología, 31, pp. 3-29.

Geler, L. 2010: Andares negros, caminos blancos. Afroporteños, Estado y Nación Argentina a fines del siglo XIX. Prohistoria, Buenos Aires.

Ghidoli, M. de L. 2016: Estereotipos en negro: representaciones y autorepresentaciones visuales de afroporteños en el siglo XIX. Prohistoria, Buenos Aires.

Golberg, M. B. 1976: "La población negra-mulata de la ciudad de Buenos Aires, 1810-1840", Desarrollo Económico, 61, pp. 75-99.

Guillot, C. F. 1961: Negros rebeldes y negros cimarrones. Fariña, Fariña.

Gutiérrez, R. 1997: Barroco americano: de la pampa a los andes. Lungwers, Barcelona.

Gutiérrez, R.; De Paula, A. y Viñuales, G. 1971: La arquitectura de la confederación en el litoral fluvial. Instituto Argentino de Historia de la Arquitectura y el Urbanismo, Resistencia. 
Huseby, G. 1999: "Los instrumentos musicales en los relieves de las ruinas de Trinidad", en III Jornadas de estudios e investigación: Europa y Latinoamérica Artes visuales y música, edición en CD. Facultad de Filosofía y Letras, Buenos Aires.

Kordon, B. 1938: Candombe: Contribución al Estudio de la Raza Negra en el Río de la Plata. Continente, Buenos Aires.

Kubler, G. 1948: Mexican Architecture of the Sixteenth Century. Harvard University, Cambridge.

Lanuza, J. L. 1942: Los Morenos. Emecé, Buenos Aires.

Lewis, M. 1984: Afro-Argentine Discurse, Another Dimension of the Black Diaspora. University of Missouri Press, Columbia.

Mac Andrew, J. 1965: The Open Air Churches of Sixteenth-Century Mexico. Harvard University Press, Cambridge.

Martínez, B. T. 1920: Historia de la provincia de Entre Ríos, 3 vols. Peuser y Librería e Imprenta Inglesa, Buenos Aires y Paraná.

Mazzitelli Mastricchio, M. 2018: 'Los 'Jueces de la Medida', el rol de los agrimensores entrerrianos en el Departamento Topográfico de Entre Ríos (1849-1871)", Revista Brasileira de História da Ciência, 11, 1, pp. 7-20

Molinari, D. L. 1944: La trata de negros: datos para su estudio en el Río de la Plata. Universidad de Buenos Aires, Facultad de Ciencias Económicas, Buenos Aires.

Noel, M. 1950: El santuario de Copacabana, de La Paza a Tihauanaco, Documentos de arte colonial sudamericano, Buenos Aires.

Ortiz Oderigo, N. 1969: Calunga: Croquis del Candombe. Eudeba, Buenos Aires.

Palm, E. 1953: "Las capillas abiertas americanas y sus antecedentes en el Occidente Cristiano", Anales del Instituto de Arte Americano, 6, pp. 47-64.

Pérez Colman, C. B. 1930: La Parroquia y la ciudad de Paraná en su segundo Centenario 1730-1930. Edición del autor, Paraná.

Pérez Colman, C. B. 1937: Historia de Entre Ríos. Época Colonial (15201810). Imprenta de la Provincia, Paraná.

Pérez Colman, C. B. 1946: Paraná, 1810-1860. Los primeros cincuenta años de la vida nacional. Edición del Autor, Rosario.

Picotti, D. 1998: La presencia africana en nuestra identidad. Ediciones del Sol, Buenos Aires.

Platero, T. 2004: Piedra libre para nuestros negros: la broma y otros periódicos de la comunidad afroargentina (1873-1882). Instituto Histórico de la Ciudad de Buenos Aires.

Reula, F. 1963: Historia de Entre Ríos. Castellví, Santa Fe.

Richard, A. 2019: "La población indígena y afrodescendiente de Paraná. Categorías socioétnicas entre 1755-1824", Memoria Americana. Cuadernos de Etnohistoria, 27, 1, pp. 169-187. https://doi.org/10.34096/mace. v27i1.6337

Rodríguez Molas, R. 1957: Algunos aspectos del negro en la sociedad rioplatense. Anuario del Instituto de Investigaciones Históricas de Rosario, Rosario.

Rosal, M. A. 2001: "Negros y pardos propietarios de bienes raíces y de esclavos en el Buenos Aires de fines del periodo hispánico", Anuario de Estudios Americanos, 58, pp. 495-512. https://doi.org/10.3989/aeamer.2001.v58.i2.213
Rossi, V. 1958 [1926]: Cosas de Negros. Hachette, Buenos Aires.

Saguier, E. 1995: "La fuga esclava como resistencia rutinaria y cotidiana en el Buenos Aires del siglo XVIII", Revista de Humanidades y Ciencias Sociales, 1, pp. 115-184.

Schávelzon, D. 1995: Excavaciones en la Imprenta Coni. Corregidor, Buenos Aires.

Schávelzon, D. 2001: "La cerámica de la población africana de Buenos Aires y Santa Fe (siglos XVIII y XIX)", en Actas del Congreso Nacional de Arqueología, I, pp. 501-508. La Plata.

Schávelzon, D. 2002: “Arqueología de la población afro-argentina: inicio, estado actual y posibilidades", en Actas del Primer Congreso Nacional de Arqueología Histórica, pp. 76-85. Corregidor, Buenos Aires.

Schávelzon, D. 2003: Buenos Aires Negra. Arqueología de una ciudad silenciada. Emecé, Buenos Aires.

Schávelzon, D. 2010: "The Vanishing People: the Archaeology of the Afro Population in Buenos Aires", en A. Ogundiran y T. Falola (eds.), Atlantic Africa and the African Dispora, pp. 373-382. Indiana University Press, Bloomigton.

Schávelzon, D. 2013: "De Cerveza y esclavos en Buenos Aires. El mercado Negrero de Retiro debajo de la Fábrica Bieckert”, Teoría y práctica de la arqueología histórica en Latinoamérica, I, 2, pp. 37-47.

Schávelzon, D. y Martínez, M. 2017: Observaciones arqueológicas en sondeos de la Capilla de San Miguel Arcángel, Paraná: informe preliminar. Centro de Arqueología Urbana, Buenos Aires. http://www.iaa.fadu.uba. ar/cau/8942

Schávelzon D. y Zorzi, F. 2014: “Afro-Argentine Archaeology: A Case of Short-Sighted Academic Racism during the Early Twentieth Century", The Journal of Pan African Studies, 7, 7, pp. 93-107.

Soiza Reilly, J. J. 1905: "Gente de color", Caras y Caretas, 25 noviembre.

Sors, O. 1981: Paraná, dos siglos y cuarto de su evolución urbana 17301955. Colmegna, Santa Fe.

Stadler, N. 2015: "Arqueología Afro ¿Es posible una arqueología de la diáspora africana en Argentina?”, en J. F. Martinez Peria y M. L. Ghidoli (comps.), Estudios afrolatinoamericanos 2. Actas de las Cuartas Jornadas del GEALA. Edición en CD.

Studer, E. F. S. 1958: La Trata de Negros en el Río de la Plata durante el siglo XVIII.

Tardieu, J.-P. 2005: "Los inicios del ministerio de negros en la provincia jesuítica del Paraguay", Anuario de Estudios Americanos, 62, pp. 141-160. https://doi.org/10.3989/aeamer.2005.v62.i1.71

Weaver, B. J. M. 2018: "Rethinking the political economy of slavery: the hacienda aesthetic at the Jesuit vineyards of Nasca, Peru", Post-Medieval Archaeology, 52, 1, pp. 117-133. https://doi.org/10.1080/00794236.2018. 1461330

Zorzi, F. 2015: "La Arqueología de la diáspora africana en la Argentina. Desarrollo, problemáticas y perspectivas", Revista de Arqueología Histórica Argentina y Latinoamericana, 9, 2, pp. 5-26. 